\title{
BOTÁNICA
}

\section{LA ICONOGRAFÍA VEGETAL EN PIEDRA EN EL TAJ MAHAL (AGRA, INDIA) Y SU ASIGNACIÓN TAXONÓMICA*}

\author{
Diego Giraldo-Cañas**
}

\begin{abstract}
RESUMEN
Giraldo-Cañas, D.: La iconografía vegetal en piedra en el Taj Mahal (Agra, India) y su asignación taxonómica. Rev. Acad. Colomb. Cienc. 37 (143): 189-205, 2013. ISSN 0370-3908.

La iconografía ha involucrado el estudio, la descripción, la clasificación y la interpretación de un ícono, y la correlación de fuentes textuales con la evidencia del ícono. Los estudios sobre la iconografía de la India se han enfocado principalmente en la identificación, la terminología y la clasificación de la amplia imagenería religiosa. Sin embargo, los estudios sobre la iconografía vegetal india permanecen sin desarrollo alguno. El Taj Mahal ha sido considerado como uno de los más bellos edificios del mundo, e inclusive el más bello; éste representa la cúspide del Estilo Mogol. Sus paredes externas e internas están profusamente ornamentadas con relieves y "pietra dura" de motivos florales (flores, frutos, plantas), que combinan influencias persas, indias y occidentales. Este estudio se enmarcó en el principio de los análisis iconográficos y así, se analizó la iconografía vegetal del Taj Mahal. Se reconocieron 46 especies, representantes de 42 géneros y 29 familias. En este artículo se presentan el nombre taxonómico, los nombres vulgares y la asignación de las familias de cada planta reconocida, así como el estilo morfológico de la iconografía vegetal. Se reconocieron cuatro estilos morfológicos. Se espera que este artículo abra nuevas posibilidades de investigación, disfrute y entendimiento de las amplias fuentes de la iconografía vegetal en la India.
\end{abstract}

Palabras clave: Arte Mogol, Estilo Mogol, Flora de la India, Iconografía vegetal, Paneles florales en piedra.

\begin{abstract}
Iconography had involved the study, description, classification, and interpretation of an icon by sourcing and correlating textual sources with the evidence of the icon. Studies in Indian iconography had remained focused on identifications, terminology, and classifications, specifically in relation to the plethora of religious imagery. However, the studies on Indian plant iconography remain without development. The Taj Mahal has been long considered one of the most, if not the most, beautiful building in the world; it represents the apex of the Mughal Style. The external and internal walls are profusely ornamented with reliefs and stone inlays ("pietra dura") of
\end{abstract}

* Artículo derivado del proyecto “Análisis de la iconografía vegetal en varias culturas y épocas” de la Universidad Nacional de Colombia, Bogotá D. C., Colombia.

** Herbario Nacional Colombiano “COL”, Instituto de Ciencias Naturales, Facultad de Ciencias, Universidad Nacional de Colombia, Bogotá D. C., Colombia.dagiraldoc@unal.edu.co 


\begin{abstract}
flowers, fruits, and plants that combine Persian, Indian, and Western influences. This study was based on premises of iconographic analyses, and thus, the Taj Mahal's plant iconography was studied. Forty six species were recognized, which represent 42 genera and 29 families. In this paper I give the botanical, popular and family name of each identified plant, as well as the morphological style of the plant iconography. Four morphological styles were identified. My hope is that this paper will open up new possibilities of research, enjoyment, and understanding in the vast resources of the plant iconography in India.
\end{abstract}

Key words: Flora of India, Floral panels in stone, Mughal Art, Mughal Style, Plant iconography.

\section{Introducción}

Los mogoles establecieron un imperio, el Imperio Mogol (Mughal Empire), que en su cúspide se extendió a través de casi todo el norte de la India, entre los años 1526 y 1857 (Kossak \& Watts, 2001). Sus numerosos legados están representados en una arquitectura monumental, una exquisita pintura, una elegante decoración, una bella caligrafía, lujosos y delicados utensilios y joyas, así como suntuosos textiles y tapetes, lo que se conoce como el Arte Mogol o el Estilo Mogol (Mughal Art o Mughal Style) (Misbach, 2003; Michell, 2007). El Estilo Mogol no es una invención de un único artista ni de un grupo de artistas, sino una creación conciente de una línea de gobernantes mogoles que encargaron, supervisaron y financiaron generaciones de arquitectos, calígrafos, pintores y artesanos por un periodo de más de 250 años (Michell, 2007).

El estilo y la decoración mogoles se caracterizan por su variado, cargado y elegante ornamento de las edificaciones, en las que predomina la armonía, la simetría y la geometría (Misbah, 2003; Ziauddin, 2005; Goel, 2007; Michell, 2007; Sharma et al., 2009; Dadlani, 2010; Wilson, 2011), tanto en sus partes externas como internas. Este ornamento incluye una fascinante combinación de elementos de la naturaleza como animales - principalmente aves- y flores, lo que refleja el gran interés que tuvieron los gobernantes mogoles por la flora y la fauna (Kossak \& Watts, 2001; Michell, 2007), así como la omnipresencia de la naturaleza en sus vidas (Michell, 2007), lo que se ve plasmado, además, en los jardines, los cuales son un símbolo del paraíso (O'Connell \& Airey, 2007). Es quizás por esto que pocos países y civilizaciones han celebrado y practicado tan consistentemente las artes decorativas, el embellecimiento y la ornamentación de superficies con motivos de la naturaleza como la India (Wilson, 2011), y éste es quizás el país con la más rica y variada iconografía vegetal antigua en diferentes edificaciones, mientras que en otros países -tales como China, Turquía, Grecia, Egipto, Estados Unidos de América, México, Guatemala, Colombia, Ecuador, Perú, Bolivia, entre otros- predominan los motivos geométricos, faunísticos, antropomorfos y mitológicos en sus iconografías antiguas.
Uno de los grandes legados mogoles es el Taj Mahal, un gigantesco y elegante mausoleo construido por el emperador mogol Shah Jahan -entre los años 1632 y 1652 - en honor de su esposa Mumtaz Mahal, quien muriera dando a luz a su decimocuarto hijo (Havell, 1920; Janick et al., 2010; Baxter et al., 2011; Raezer \& Raezer, 2012). El Taj Mahal representa la cúspide del Estilo Mogol y éste constituye una de las maravillas del mundo (Kennedy, 2007; Dadlani, 2010; Janick et al., 2010; Baxter et al., 2011; Raezer \& Raezer, 2012). Esta maravilla arquitectónica representa un complejo de edificios (mausoleo, mezquita, jardines y portal del complejo), dispuestos en 1,7 ha (Janick et al., 2010) (Figuras 1 y $2 \mathrm{~A})$.
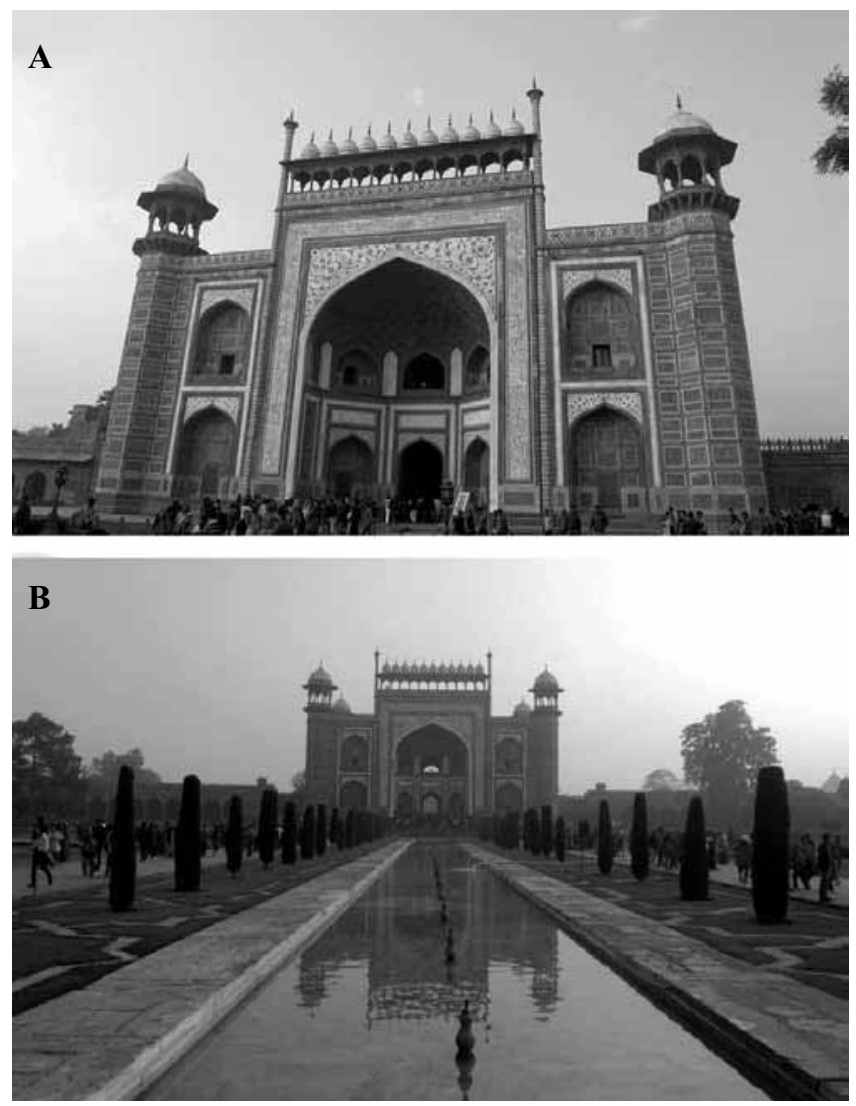

Figura 1. Portal del complejo del Taj Mahal. A. Vista frontal; B. Vista desde el mausoleo (fotografías: D. Giraldo-Cañas). 

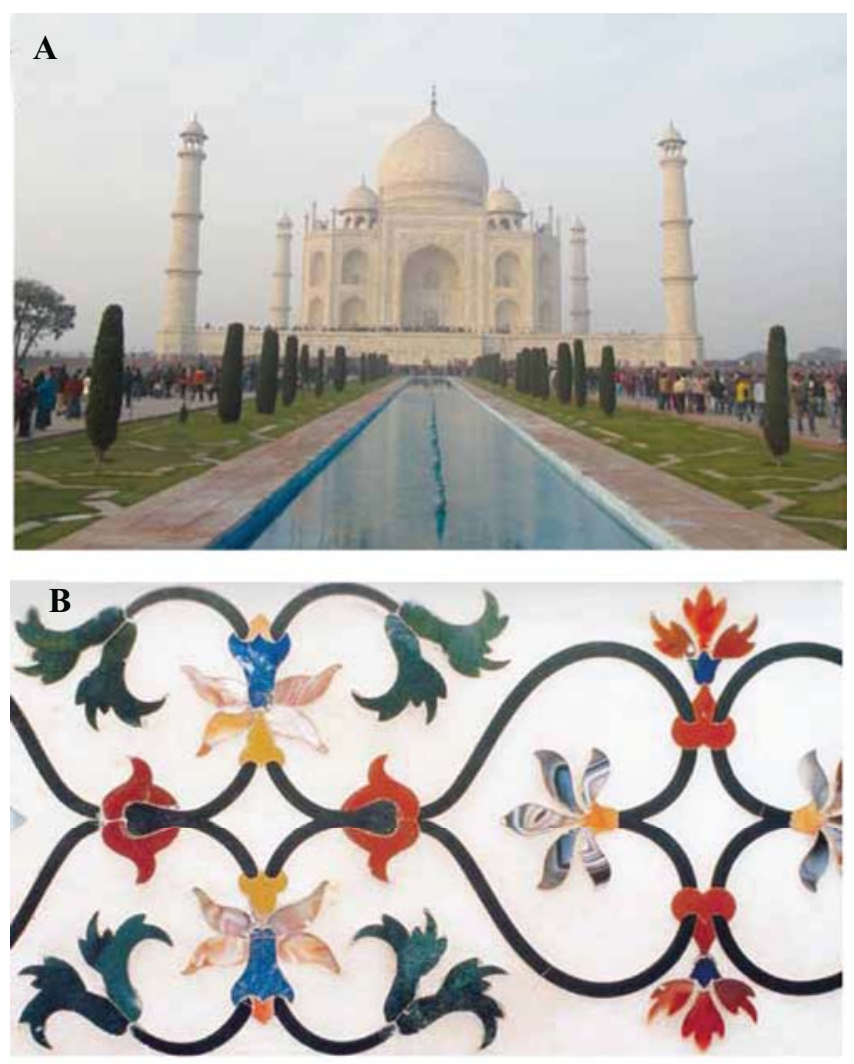

Figura 2. A. Vista frontal del mausoleo del Taj Mahal (fotografía: D. Giraldo-Cañas); B. Decoración del mausoleo del Taj Mahal con la técnica de la "pietra dura" (de Janick et al., 2010). Los colores de la Figura 2B corresponden a diferentes piedras preciosas y semipreciosas [ágata, ametista, cristal, jade, lapis-lázuli, topacio, turquesa, zafiro, entre otras (Smith, 1901)], las cuales están incrustadas en el mármol.

En este complejo del Taj Mahal se conjugan todas las bellas expresiones del arte, la arquitectura y la decoración del Estilo Mogol, y es precisamente una de estas expresiones, la concerniente a los paneles florales en piedra que decoran todas las paredes de las edificaciones del complejo, de la que se ocupa este artículo. Dichos paneles florales representan una valiosa y bella iconografía vegetal en piedra (principalmente mármol, arenisca roja, piedras preciosas y semipreciosas), la que incluye hermosas y sofisticadas representaciones de plantas o partes de éstas, ya bien sea reales o imaginaciones idealizadas de las mismas, mediante básicamente tres técnicas, la "pietra dura" (Figura 2B) (Kennedy, 2007; Michell, 2007; Sharma et al., 2009; Janick et al., 2010), el relieve en piedra, tanto en mármol (Michell, 2007; Janick et al., 2010) como en arenisca roja (Michell, 2007) y el calado en mármol (Michell, 2007). Cabe destacar que dicha iconografía vegetal está acompañada de elegantes caligrafías con textos del Corán (Figura 3).
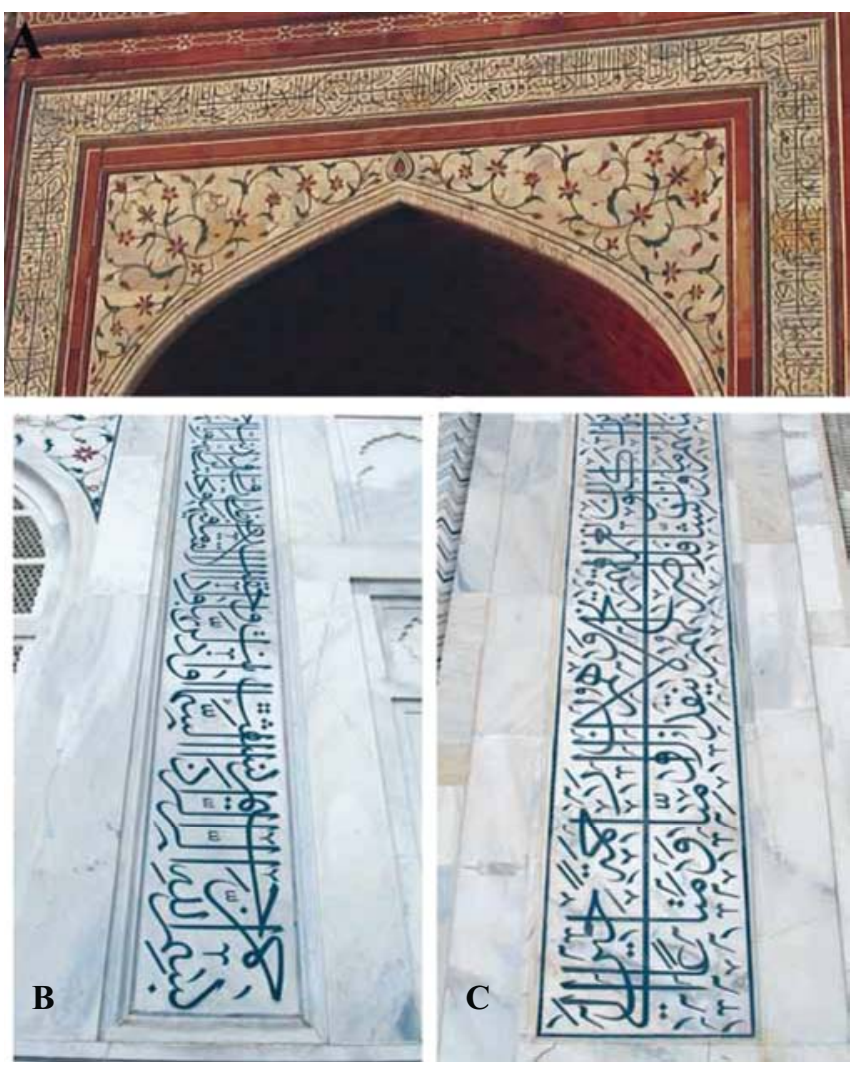

Figura 3. Caligrafías con textos del Corán como parte del ornamento del Complejo del Taj Mahal. A. Parte frontal del portal del complejo; B y C. Paredes externas del mausoleo (fotografías: D. Giraldo-Cañas).

En los últimos años, el estudio y el análisis de la iconografía vegetal ha cobrado suma importancia en diferentes latitudes, con base en los trabajos de Eisendrath (1961), Heyden (1983), Tyldesley \& Bahn (1983), Taube (1986), Zeven \& Brandenburg (1986), Fernández Pérez (1989, 1990), Johannessen \& Parker (1989), Díaz-Piedrahita (1991, 2000), Villegas (1992), Gupta (1996), Luna (1996), Antei (1997), Bye \& Linares (1999), Díaz (1999), Fresquet Febrer \& López Terrada (1999), Lozoya (1999), Velasco Lozano (1999), Viesca Treviño (1999), Nieto Olarte (2000), Leal del Castillo (2001), Rueda González (2001), Misbah (2003), Janick \& Caneva (2005), Pavord (2005), White Olascoaga \& Zepeda Gómez (2005), Janick \& Paris (2006a, 2006b), Cervantes (2006), León-Portilla (2006), Linares \& Bye (2006), Pacheco (2006), Proulx (2006), Uriarte (2006), Velasco Lozano \& Nagao (2006), Daunay \& Janick (2007, 2008), Daunay et al. (2007a, 2007b, 2008), Goel (2007), Hummer \& Janick (2007), Janick (2007a, 2007b, 2010, 2012), Janick \& Daunay (2007), Kennedy (2007), Michell (2007), Sharma et al. (2009), Janick et 
al. (2010), Macaulay-Lewis (2010), Stolarczyk \& Janick (2011), Wilson (2011), Díaz-Piedrahita \& Fernández Alonso (2012), Teron \& Borthakur (2012) y Giraldo-Cañas (2013). Cabe destacar que Janick et al. (2010) realizaron un estudio de la iconografía vegetal del Taj Mahal, pero dicho estudio sólo documentó la existencia de 23 especies en el mausoleo. No obstante y a pesar de este auge, aún falta mucho por analizar la iconografía vegetal a lo largo de la historia de la humanidad.

El estudio de la iconografía de la India se ha centrado en las diversas expresiones religiosas, mitológicas (Gopinatha Rao, 1914; Rao, 1916; MacDonell, 1918; Venkateswara, 1918; Coomaraswamy, 1928, 1929, 1998; Bhatla et al., 1984; Patnaik, 1993; Gupta, 1996, 2001; Kossak \& Watts, 2001; Tawari, 2003; Dhar, 2011), artísticas, artesanales (Smith, 1901; Kossak \& Watts, 2001; Misbach, 2003; Goel, 2007; Kennedy, 2007; Michell, 2007; Sharma et al., 2009; Dhar, 2011; Wilson, 2011; Karolia \& Ladia, 2012; Teron \& Borthakur, 2012) o de usos de las plantas (Patnaik, 1993; Nayar et al., 1999; Gupta, 2001; Mathur, 2012; Patil, 2012), y no en los análisis de la iconografía vegetal y de su asignación taxonómica, salvo los trabajos de Gupta (1996), Janick et al. (2010) y Giraldo-Cañas (2013) para numerosos templos (budistas, hindúes, jaines), el Taj Mahal y el Templo Karni Mata, respectivamente.

Este artículo no constituye un análisis de la arquitectura del Taj Mahal, sino un aporte en la interpretación de la iconografía vegetal, así como una asignación taxonómica de las diferentes imágenes florales de este complejo, con el objetivo de contribuir al conocimiento de las plantas empleadas como ornamento en decoraciones arquitectónicas mogolas en la India. Este trabajo busca, además, sensibilizar a las personas sobre la gran importancia que tiene la iconografía vegetal en sus diferentes expresiones culturales en la India. Adicionalmente, este artículo pretende ser un testimonio y un tributo a todos esos pueblos que a lo largo de la historia de la India, nos dejaron esta maravillosa faceta de la sensibilidad y el profundo aprecio por la naturaleza y en especial, por su rica y variada flora, considerada una de las diez más diversas del planeta con cerca de 17 mil especies (Venu, 1998).

\section{Marco metodológico}

La iconografía se define, según la Real Academia Española de la Lengua (2001), como la "descripción de imágenes, retratos, cuadros, estatuas o monumentos, y especialmente de los antiguos"; mientras que ícono" se define como el "signo

* La Real Academia de la Lengua Española acepta el uso de las palabras ícono e icono, esdrújula y grave, respectivamente. En este artículo se emplea la forma esdrújula, ya que ésta es la más usada. que mantiene una relación de semejanza con el objeto representado" [véase en Eisendrath (1961) la historia de estos dos conceptos]. Por su parte, Sondereguer (2004: 73) considera que la iconografía "es toda obra plástica, artesanal o artística", mientras que ícono lo considera como "toda aquella obra plástica". Entre tanto, Proulx (2006) y Dhar (2011) mencionan que la iconografía, en el sentido convencional, ha involucrado el estudio, la descripción, la clasificación y la interpretación de un ícono, y la correlación de fuentes textuales con la evidencia del ícono. En suma y en palabras de Rueda González (2001), "las artes y las ciencias se valen de imágenes".

Este trabajo se enmarcó en el principio de los análisis iconográficos (Pang, 1992; Sondereguer, 2004; Mason et al., 2006; Proulx, 2006; Munsterberg, 2009; Dhar, 2011), el cual se refiere al método analítico descriptivo-morfológico, vinculado al aspecto antropológico e histórico-cultural de las obras plásticas (íconos) (Sondereguer, 2004). En resumen, este método realiza una descripción morfológica, modal, estilística y técnica, o sea, una clasificación iconográfica con base en los postulados expuestos por Pang (1992), Sondereguer (2004), Proulx (2006) y Dhar (2011). Se siguió a Sondereguer (2004) para la consideración y la clasificación de los estilos morfológicos de la iconografía del Taj Mahal, esto es, los estilos primarios se dividen en Figurativo (naturalista e idealista) y Abstracto (figurativo, geométrico y concreto).

Es necesario destacar que en este artículo se habla de "asignación taxonómica" y no de "determinación taxonómica" y mucho menos de "identificación taxonómica", toda vez que para un proceso de determinación de especies vegetales se requiere de ejemplares de herbario y/o ilustraciones científicas, que en algunos casos pueden estar acompañados de fotografías del material in vivo, mientras que en el presente artículo se analizan fotografías de la iconografía vegetal. En el sentido de De La Sota (1982: 2), las unidades se clasifican, los ejemplares se determinan y dado que las categorías taxonómicas son por definición conceptos de clases de individuos, una planta o un animal concreto se "determina" no se "identifica"; así, la identidad sólo funciona con respecto al individuo. Por lo tanto, las asignaciones taxonómicas dadas aquí corresponden a interpretaciones del autor con base en la evidencia de los íconos analizados y en ningún momento, se deben considerar "determinaciones taxonómicas".

La toma de la información procede de datos directos in situ, a partir de un extenso registro fotográfico realizado por el autor, entre finales de 2012 y comienzos de 2013, así como de datos secundarios (véase la literatura citada). Cabe destacar que no se muestran todas las fotografías de las especies asignadas en la iconografía en piedra del Taj Mahal, ya bien 
sea por cuestiones de extensión del manuscrito o, porque la calidad de las mismas no era la adecuada para reproducirlas aquí. Las figuras 2B, 5, 6 y 8 corresponden a Janick $\boldsymbol{e t}$ al. (2010), las cuales fueron cedidas amablemente por estos investigadores.

La asignación taxonómica de las especies consideradas en la iconografía analizada se basó en diferentes obras botánicas, así como la categorización de especies nativas e introducidas, tales como Drury (1864), Folkard (1884), Skinner (1911), Torfrida (1944), Cowen (1952), Randhawa (1957), Dahlgren \& Clifford (1982), Dahlgren et al. (1985), Goldberg (1989), Jones (1993), Patnaik (1993), Gupta (1996), Mabberley (1998), Schultes \& Hofmann (2000), Swerdlow (2000), Kumar Sud \& Kumar (2004), Page \& Olds (2004), Pavord (2005), Sood et al. (2005a, 2005b), Anónimo (2007), De Rosamel \& Heinrichs (2006), Furlani Pedoja (2006), Pridgeon (2006), Webb \& Craze (2006), Mikolajski (2009), Janick et al., (2010), Singh (2010), Joshi (2012) y Giraldo-Cañas (2013). Del mismo modo, la asignación taxonómica también se basó en el análisis de varias fotografías de la flora india tomadas por el autor de esta contribución, y en las imágenes y las fotografías contempladas en varias páginas web, principalmente "www.flowersofindia.net", la cual tiene una enorme galería fotográfica de plantas indias. Asimismo, se realizaron varias confrontaciones de las asignaciones taxonómicas con ejemplares botánicos depositados en el Herbario Nacional Colombiano "COL” (Bogotá D. C.), en el Herbario Amazónico Colombiano "COAH” (Bogotá D. C.), así como en el Herbario del Jardín Botánico de Missouri "MO" (fotografías de especímenes dispuestas en su página web). Dado que para la mayoría de las especies aquí mencionadas se encuentran excelentes fotografías in vivo en la internet, éstas no se presentan aquí y por lo tanto, se recomienda ver principalmente "www.flowersofindia.net".

Cabe destacar que en algunos casos, la parte vegetativa no corresponde con la parte reproductiva de las plantas empleadas en la iconografía, ya que se combinan, de manera idealizada, flores de monocotiledóneas dispuestas en ramas y hojas de eudicotiledóneas. Por lo tanto, la asignación taxonómica puede corresponder, en primera instancia, a la parte reproductiva, y si las características de la parte vegetativa (hojas) permiten un reconocimiento taxonómico, se procedía a tal fin. El arreglo de familias y géneros de gimnospermas se basó en Christenhusz et al. (2011), mientras que el arreglo de familias de angiospermas se basó en el APG III (Reveal \& Chase 2011). Los nombres vulgares de las especies se dan en inglés, para que así éstos sean más fácilmente reconocidos en un contexto indio; en la mayoría de los casos, dichos nombres se tomaron de "www.flowersofindia.net".

\section{Resultados y discusión}

Se reconocieron 46 especies, representantes de 42 géneros y 29 familias; de éstas, la familia Liliaceae presentó seis asignaciones taxonómicas, seguida de las Asteraceae y las Ranunculaceae, con cuatro especies cada una. Así, el número de asignaciones taxonómicas para la iconografía vegetal del complejo del Taj Mahal se eleva significativamente (46 especies), ya que Janick et al. (2010), sólo documentaron la existencia de 23 especies.

Las asignaciones taxonómicas se detallan a continuación:

\section{Gimnospermas}

\section{Cupressus sempervirens $\mathbf{L}$.}

Familia: Cupressaceae.

Estatus: Introducida del Mediterráneo.

Nombres vulgares: Funeral cypress, graveyard cypress, italian cypress, mediterranean cypress, pencil pine.

Técnica de la iconografía: Árbol idealizado en arenisca roja (en la mezquita).

Estilo morfológico primario: Figurativo idealista. Iconografía: Figura 4A.
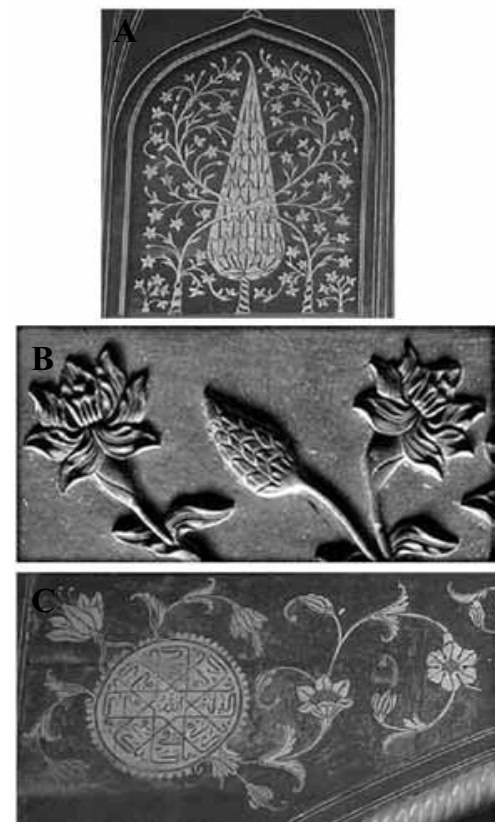

Figura 4. Motivos florales en arenisca roja en la mezquita del Taj Mahal. A. Un arbolito de Cupressus sempervirens L., rodeado de ramas floríferas escandentes de Combretum indicum (L.) DeFilipps; B. Inflorescencia de Zingiber cf. zerumbet (L.) Roscoe ex Sm., en medio de dos flores de Crinum latifolium L.; C. Lilium martagon L. (flor superior izquierda), Luffa cylindrica M. Roem. (flor del extremo derecho, fruto de la parte centro-superior) y $\mathrm{Ca}$ lendula sp. (capítulo central) (fotografías: D. Giraldo-Cañas). 


\section{Cycas sp.}

Familia: Cycadaceae.

Estatus: Nativa (?).

Nombres vulgares: King sago palm, sago cycad, sago palm. Técnica de la iconografía: Tallos tuberosos en alto relieve en arenisca roja, los que están dispuestos en la base de varios paneles florales de la mezquita; de cada tallo de las Cycas emergen tres ramas floríferas con hojas de una eudicotiledónea indeterminada, con varias flores (e.g. Iris cf. germanica L. y Narcissus sp.).

Estilo morfológico primario: Figurativo idealista.

Iconografía: Michell (2007: 171).

\section{Angiospermas basales}

\section{Magnolia sp.}

Familia: Magnoliaceae.

Estatus: Nativa (?).

Nombres vulgares: Magnolia.

Técnica de la iconografía: Talla en mármol (infrutescencia) usada para el remate de barandas externas del mausoleo. Estilo morfológico primario: Figurativo idealista.

\section{Monocotiledóneas}

\section{Coelogyne sp.}

Familia: Orchidaceae.

Estatus: Nativa.

Nombres vulgares: Angel orchid.

Técnica de la iconografía: Flores en pietra dura.

Estilo morfológico primario: Figurativo idealista.

Nota: Janick et al. (2010) mencionaron los nombres Anemone sp. o Ranunculus sp. asignables a su figura 4-B, pero la flor de la porción derecha de dicha figura corresponde, con base en su morfología peculiar, a una especie de la familia Orchidaceae, asignable a Coelogyne sp. Esta asignación también se le da aquí a las dos flores centro-laterales de la figura 4-C de Janick et al. (2010).

Iconografía: Figuras $5 \mathrm{~B}$ y $5 \mathrm{C}$.

\section{Crinum latifolium $\mathrm{L}$.}

Familia: Amarillydaceae.

Estatus: Nativa (?)

Nombres vulgares: Ceylon swamplily, milk lily, pink striped trumpet lily, wine lily.

Técnica de la iconografía: Flores en pietra dura (en el mausoleo), así como en alto relieve en arenisca roja (en la mezquita).

Estilo morfológico primario: Figurativo naturalista.

Iconografía: Figuras 4B y $6 \mathrm{~B}$.

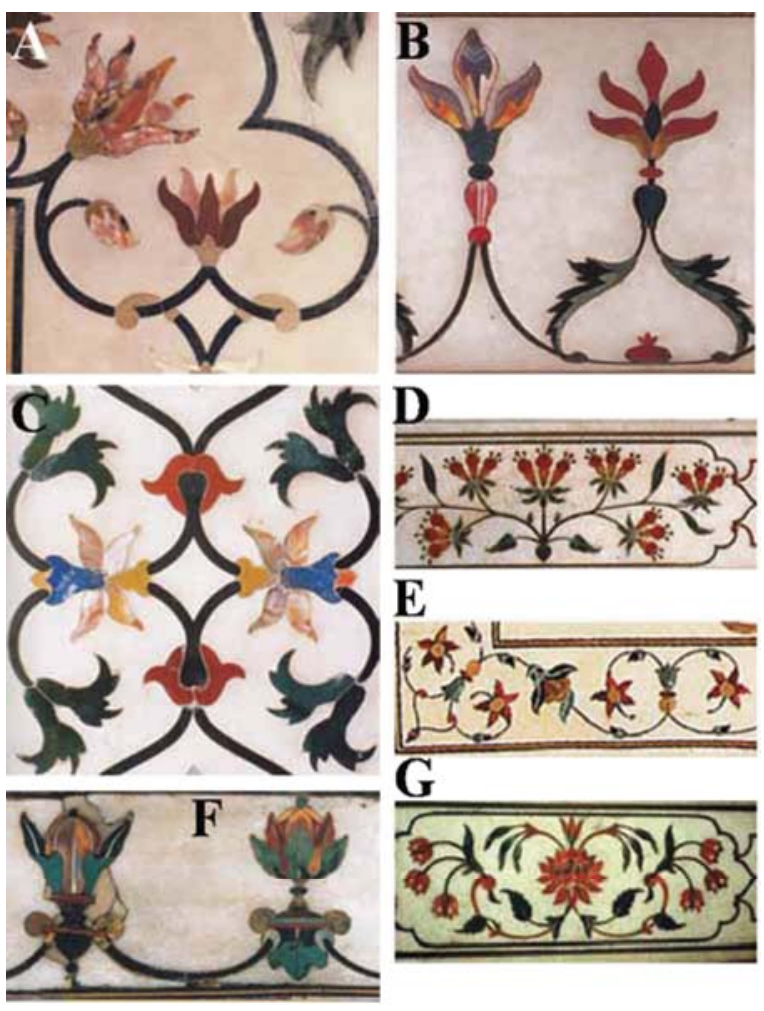

Figura 5. Ornamentación del mausoleo del Taj Mahal con motivos florales en "pietra dura". A. Lilium sp.; B. Anemone rivularis Buch.-Ham. ex D.C. (flor izquierda), y Coelogyne sp. (flor derecha); nótese un diminuto fruto de Punica granatum L. en el extremo inferior derecho; C. Aquilegia sp. (flores centrales, una en la mitad superior y la otra en la mitad inferior), Coelogyne sp. (flores centro-laterales) y Thunbergia mysorensis (Wight) T. Anderson (las cuatro flores restantes, dos a cada lado; D. Lonicera henryi Hemsl.; E. Campanula lactiflora M. Bieb.; F. Nelumbo nucifera Gaertn. (flor derecha) y flor izquierda sin asignación taxonómica;

G. Chrysanthemum indicum L. (capítulo central) y Lilium mackliniae J. R. Sealy (flores laterales) (de Janick et al., 2010).

\section{Fritillaria imperialis L.}

Familia: Liliaceae.

Estatus: Nativa de Turquía, Irán, Afganistán y Cachemira (India-Pakistán).

Nombres vulgares: Crown imperial, imperial fritillary, Kaiser's crown.

Técnica de la iconografía: Flores en pietra dura, así como en alto relieve en mármol.

Estilo morfológico primario: Figurativo naturalista. Iconografía: Figuras $6 \mathrm{E}$ y $8 \mathrm{E}$.

\section{Gloriosa superba L.}

Familia: Colchicaceae.

Estatus: Introducida de Asia oocidental. 

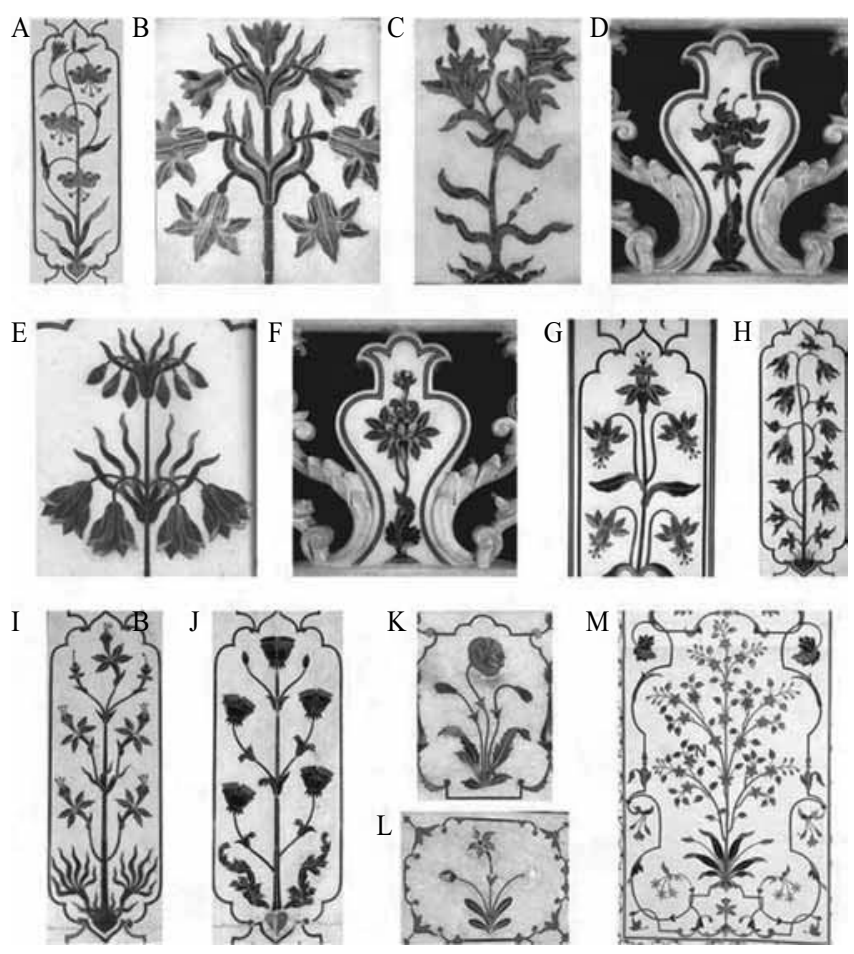

Figura 6. Ornamentación del mausoleo del Taj Mahal con motivos florales en "pietra dura". A. Lilium martagon L.; B. Crinum latifolium L.; C. Tricyrtis sp.; D. Tricyrtis sp. o Lilium sp.; E. Fritillaria imperialis L.; F. Chrysanthemum indicum L.; G. Punica granatum L.; H. Clematis sp.; I. Fuchsia cf. venusta Kunth (flores) y Paris sp. (hojas); J. Centaurea sp.; K. Papaver orientale L.; L. Primula cf. sinopurpurea Balf. f. ex Hutch.; M. Campanula lactiflora M. Bieb. (de Janick et al., 2010).

Nombres vulgares: Claw, climbing lily, gloriosa lily, glory lily, tiger's claws.

Técnica de la iconografía: Flores en pietra dura, así como en alto relieve en mármol.

Estilo morfológico primario: Figurativo naturalista.

Iconografía: Figura 8D.

\section{Hyacinthus orientalis $\mathrm{L}$.}

Familia: Asparagaceae.

Estatus: Introducida del Medio Este.

Nombres vulgares: Dutch hyacinth, hyacinth, Roman hyacinth.

Técnica de la iconografía: Alto relieve en arenisca roja (varios bulbos y sus respectivas hojas en la parte inferior de varios paneles florales de la mezquita; los bulbos están dispuestos uno a cada lado de cada tallo tuberoso de Cycas sp.). Estilo morfológico primario: Figurativo naturalista. Iconografía: Michell (2007: 171).
Iris cf. germanica L.

Familia: Iridaceae.

Estatus: Introducida de Europa.

Nombres vulgares: Bearded iris, common flag, german iris, iris.

Técnica de la iconografía: Flores, hojas y tallos en alto relieve en mármol (en el mausoleo), así como en arenisca roja (en la mezquita).

Estilo morfológico primario: Figurativo naturalista. Iconografía: Figuras 7E, 8G, 8H y 8I.
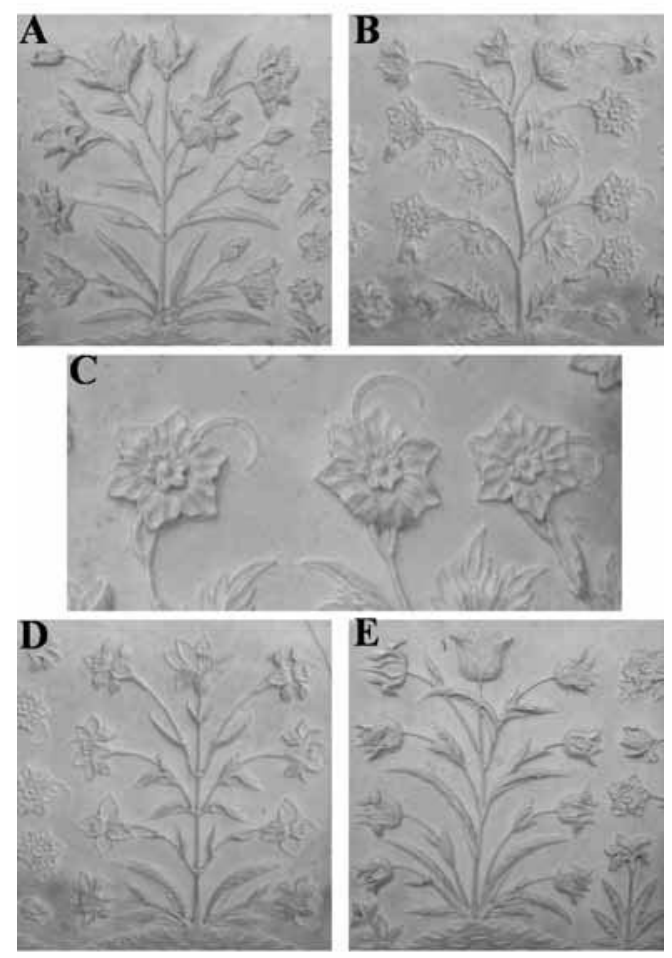

Figura 7. Motivos florales en alto relieve en mármol en el mausoleo del Taj Mahal. A. Flores de Lilium sp.; B. Flores de Narcissus sp., las que salen de ramas con hojas de Artemisia absinthium L.; C. Flores de Narcissus sp.; D. Flores de Pancratium sp. (acompañadas de tres flores de Narcissus sp. en el extremo lateral izquierdo); E. Rama florífera de Tulipa sp., con una planta pequeñita a cada lado asignable a Iris cf. germanica L. (acompañadas de dos flores de Narcissus sp. en el extremo lateral derecho) (fotografías:

$$
\text { D. Giraldo-Cañas). }
$$

\section{Lilium mackliniae J. R. Sealy}

Familia: Liliaceae.

Estatus: Nativa.

Nombres vulgares: Siroi lily.

Técnica de la iconografía: Flores en pietra dura.

Estilo morfológico primario: Figurativo naturalista.

Iconografía: Figura 5G. 

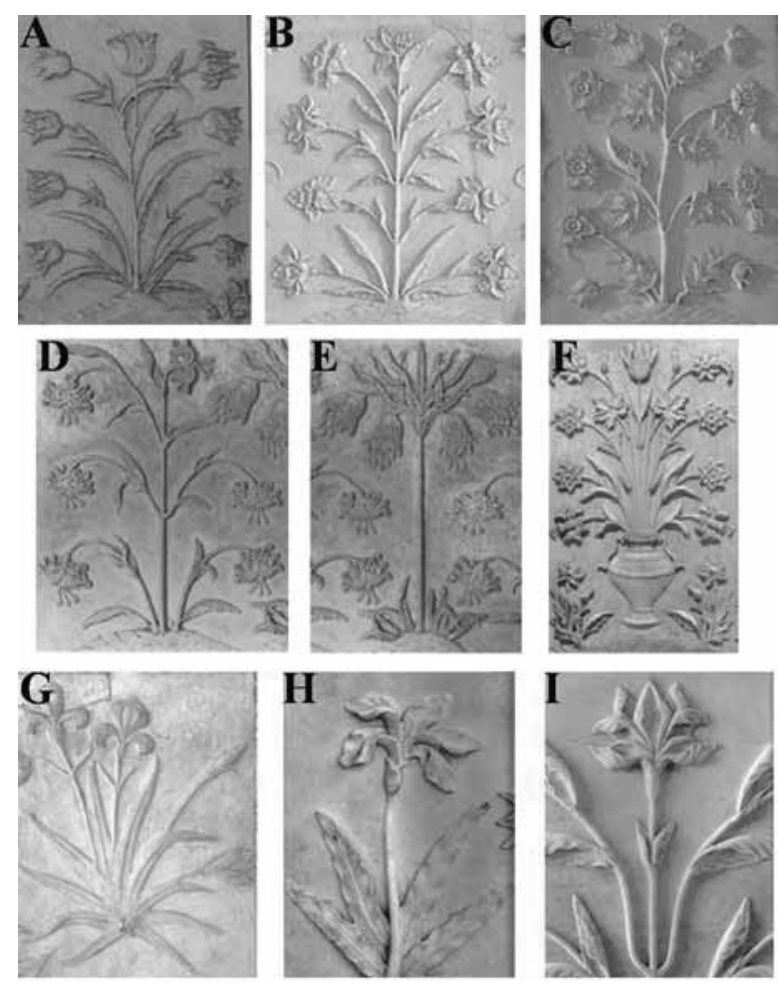

Figura 8. Motivos florales en alto relieve en mármol en el mausoleo del Taj Mahal. A. Lilium sp.; B. Pancratium sp.; C. Anemone rivularis Buch.-Ham. ex D.C. con Tulipa sp. en la base; D. Gloriosa superba L.; E. Fritillaria imperialis L.; F. Tulipa sp. (flor central superior), Vitis vinifera L. (dos hojas centro laterales), acompañadas a lado y lado de Anemone rivularis Buch.-Ham. ex D.C., Narcissus sp. y Pancratium sp., con dos plantas de Anemone rivularis Buch.-Ham. ex D.C. en la base del florero; G, H e I. Iris cf. germanica L. (nótese en I que las hojas son de una Eudicotiledónea) (de Janick et al., 2010).

\section{Lilium martagon $\mathrm{L}$.}

Familia: Liliaceae.

Estatus: Introducida de Asia Menor y Mongolia.

Nombres vulgares: Turk's cap lily.

Técnica de la iconografía: Flores en pietra dura (en el mausoleo), así como en arenisca roja (en la mezquita).

Estilo morfológico primario: Figurativo naturalista.

Iconografía: Figuras 4C y $6 \mathrm{~A}$.

\section{Lilium sp.}

Familia: Liliaceae.

Estatus: Nativa (?).

Nombres vulgares: Dzokou lily.

Técnica de la iconografía: Flores en alto relieve en mármol.

Estilo morfológico primario: Figurativo naturalista.

Iconografía: Figuras 5A, 7A, 8A y 10F.

\section{Narcissus sp.}

Familia: Amaryllidaceae.

Estatus: Nativa (?).

Nombres vulgares: Daffodil, narcissus.

Técnica de la iconografía: Flores en alto relieve en mármol (en el mausoleo), así como en arenisca roja (en la mezquita). Estilo morfológico primario: Figurativo naturalista.

Iconografía: Figuras 7B, 7C, 7D, 7E y 8F.

\section{Pancratium sp.}

Familia: Amaryllidaceae.

Estatus: Introducida del Mediterráneo.

Nombres vulgares: Sea lily.

Técnica de la iconografía: Flores en alto relieve en mármol.

Estilo morfológico primario: Figurativo naturalista.

Iconografía: Figuras 7D, 8B y 8F.

\section{Paris sp.}

Familia: Melanthiaceae.

Estatus: Introducida de Eurasia.

Nombres vulgares: Paris.

Técnica de la iconografía: Hojas en pietra dura (las hojas están dispuestas en la base de una rama florífera de Fuchsia cf. venusta.

Estilo morfológico primario: Figurativo idealista.

Iconografía: Figura $6 \mathrm{I}$.

\section{Tricyrtis sp.}

Familia: Liliaceae.

Estatus: Nativa (?).

Nombres vulgares: Toad lily.

Técnica de la iconografía: Flores y hojas en pietra dura (en el mausoleo), así como en alto relieve en arenisca roja (en la mezquita).

Estilo morfológico primario: Figurativo naturalista.

Iconografía: Figura 6C.

\section{Tulipa sp.}

Familia: Liliaceae.

Estatus: Introducida de Eurasia.

Nombres vulgares: Tulip.

Técnica de la iconografía: Flores en pietra dura, así como en alto relieve en mármol.

Estilo morfológico primario: Figurativo naturalista.

Iconografía: Figuras 7E, 8C y 8F.

\section{Zingiber cf. zerumbet (L.) Roscoe ex Sm.}

Familia: Zingiberaceae.

Estatus: Nativa.

Nombres vulgares: Pinecone ginger, shampoo ginger, wild ginger.

Técnica de la iconografía: Inflorescencia en alto relieve en arenisca roja (en la mezquita). 
Estilo morfológico primario: Figurativo naturalista.

Iconografía: Figura 4B.

\section{EUdicotiLEDónEAS}

\section{Acanthus cf. mollis $\mathrm{L}$.}

Familia: Acanthaceae.

Estatus: Introducida del Mediterráneo.

Nombres vulgares: Acanthus, bear's breeches, candelabrus.

Técnica de la iconografía: Hojas en alto relieve en mármol (en la base y los remates de algunas pequeñas columnas del mausoleo).

Estilo morfológico primario: Figurativo idealista.

Iconografía: Figuras $10 \mathrm{~A}$ y $10 \mathrm{~B}$.

\section{Anemone rivularis Buch.-Ham. ex D.C.}

Familia: Ranunculaceae.

Estatus: Nativa.

Nombres vulgares: River anemone, river windflower, windflower.

Técnica de la iconografía: Flores en pietra dura, así como en alto relieve en mármol.

Estilo morfológico primario: Figurativo naturalista.

Iconografía: Figuras 5B, 8C y 8F.

\section{Aquilegia sp.}

Familia: Ranunculaceae.

Estatus: Introducida.

Nombres vulgares: Columbine.

Técnica de la iconografía: Flores en pietra dura.

Estilo morfológico primario: Figurativo idealista.

Iconografía: Figuras 5C y $10 \mathrm{C}$.

\section{Artemisia absinthium $\mathbf{L}$.}

Familia: Asteraceae.

Estatus: Nativa.

Nombres vulgares: Absinthe, common wormwood.

Técnica de la iconografía: Hojas en alto relieve en mármol.

Estilo morfológico primario: Figurativo naturalista.

Iconografía: Figura 7B.

\section{Butea monosperma (Lam. ) Taub.}

Familia: Fabaceae.

Estatus: Nativa.

Nombres vulgares: Flame of the forest.

Técnica de la iconografía: Flores en pietra dura.

Estilo morfológico primario: Figurativo idealista.

Iconografía: Figura 10F.

\section{Calendula sp.}

Familia: Asteraceae.

Estatus: Introducida de Europa.

Nombres vulgares: Calendula, marigold.

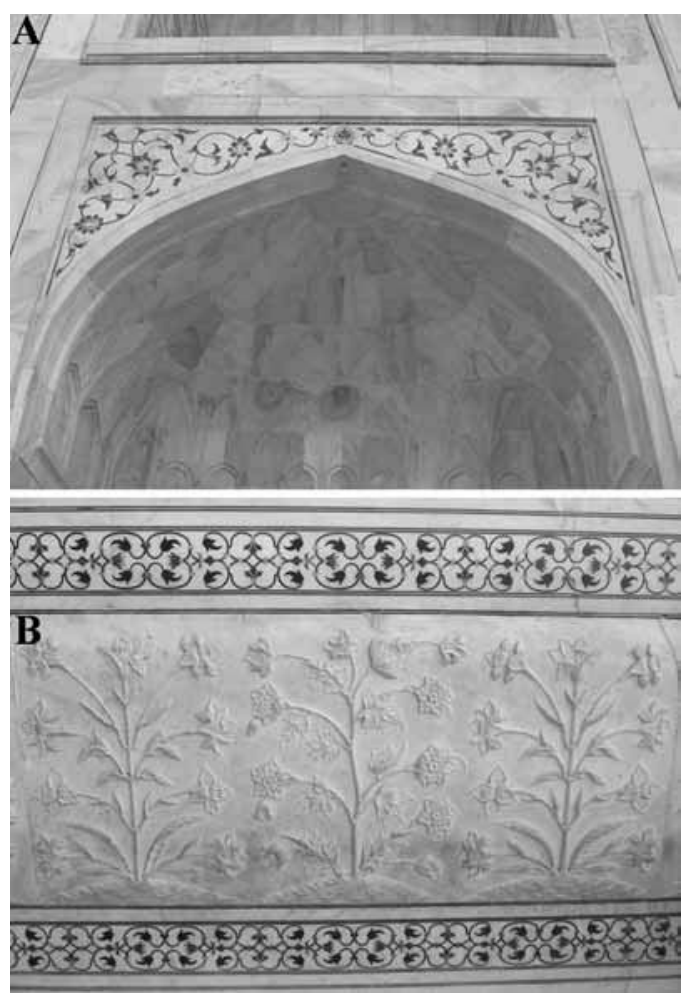

Figura 9. Ornamentación del mausoleo del Taj Mahal con motivos florales en "pietra dura". A. Uno de los arcos laterales externos del mausoleo; B. Paneles de la parte interna del mausoleo con decoración en alto relieve en mármol con cintas horizontales en "pietra dura", tanto en la parte superior como en la parte inferior del panel floral (fotografías: D. Giraldo-Cañas).

Técnica de la iconografía: Flores en pietra dura (en el mausoleo), así como en arenisca roja (en la mezquita). Estilo morfológico primario: Figurativo idealista. Iconografía: Figura 4C.

\section{Campanula lactiflora M. Bieb.}

Familia: Campanulaceae.

Estatus: Introducida de Turquía y el Cáucaso.

Nombres vulgares: Bellflower.

Técnica de la iconografía: Flores en pietra dura. Estilo morfológico primario: Figurativo naturalista. Iconografía: Figuras 5E y $6 \mathrm{M}$.

\section{Centaurea sp.}

Familia: Asteraceae.

Estatus: Introducida de Eurasia.

Nombres vulgares: Cornflower, knapweed.

Técnica de la iconografía: Flores en pietra dura.

Estilo morfológico primario: Figurativo naturalista en unas ocasiones, así como figurativo idealista en otras. 
Nota: Janick et al. (2010) le asignaron el nombre de Papaver orientale a su figura 5-J (la cual es figurativa naturalista), pero las unidades florales de dicha figura corresponden a capítulos y no a flores individuales, los cuales, por su morfología, aquí son asignados a Centaurea sp.

Iconografía: Figuras 6J, 10E, 11A y 11B.

\section{Chrysanthemum indicum $\mathrm{L}$.}

Familia: Asteraceae.

Estatus: Nativa.

Nombres vulgares: Chrysanthemum.

Técnica de la iconografía: Flores en pietra dura.

Estilo morfológico primario: Figurativo naturalista.

Iconografía: Figuras $5 \mathrm{G}$ y $6 \mathrm{~F}$.

\section{Clematis sp.}

Familia: Ranunculaceae.

Estatus: Introducida (?).

Nombres vulgares: Clematis, traveller's joy, virgin's bower.

Técnica de la iconografía: Flores en pietra dura.

Estilo morfológico primario: Figurativo idealista.

Iconografía: Figuras $6 \mathrm{H}, 10 \mathrm{E}$ y $10 \mathrm{~F}$.

\section{Combretum indicum (L.) DeFilipps}

Familia: Combretaceae.

Estatus: Nativa.

Nombres vulgares: Burma creeper, rangoon creeper, red jasmine.

Técnica de la iconografía: Flores en arenisca roja (en la mezquita).

Estilo morfológico primario: Figurativo naturalista.

Iconografía: Figura 4A.

\section{Delphinium sp.}

Familia: Ranunculaceae.

Estatus: Introducida (?).

Nombres vulgares: Delphinium.

Técnica de la iconografía: Flores en alto relieve en mármol.

Estilo morfológico primario: Figurativo naturalista.

Iconografía: Michell (2007: 2), Janick et al. (2010: 33) y

Wilson (2011: 195).

\section{Dianthus sp.}

Familia: Caryophyllaceae.

Estatus: Introducida de Asia Central.

Nombres vulgares: Carnation, modern pink.

Técnica de la iconografía: Flores en pietra dura.

Estilo morfológico primario: Figurativo idealista.

Iconografía: Figura 10F.

\section{Ficus carica $\mathbf{L}$.}

Familia: Moraceae.

Estatus: Introducida de Turquía.

Nombres vulgares: Anjeer, common fig.
Técnica de la iconografía: Hojas en alto relieve en mármol (en los remates de algunas pequeñas columnas del mausoleo; naturalista) y en arenisca roja (en el portal principal del complejo; idealista), así como en pietra dura en el mausoleo (idealista).

Estilo morfológico primario: Figurativo naturalista e idealista.

\section{Ficus religiosa $\mathrm{L}$.}

Familia: Moraceae.

Estatus: Nativa.

Nombres vulgares: Bodhi tree, bo tree, holy tree, peepal, peepul, peepul tree, pipal, sacred fig.

Técnica de la iconografía: Hojas en pietra dura.

Estilo morfológico primario: Figurativo idealista.

Iconografía: Figuras 10A, 10B y 11B.

\section{Fuchsia cf. venusta Kunth}

Familia: Onagraceae.

Estatus: Introducida de la América tropical.

Nombres vulgares: Fuchsia.

Técnica de la iconografía: Flores en pietra dura.

Estilo morfológico primario: Figurativo naturalista.

Nota: Janick et al. (2010) no le asignaron ningún nombre taxonómico a las unidades florales de su figura 5-I. Dadas las características de las flores, éstas con certeza corresponden a un representante del género neotropical Fuchsia, quizás a Fuchsia cf. venusta.

Iconografía: Figura 6I.

\section{Jasminum sp.}

Familia: Oleaceae.

Estatus: Nativa (?).

Nombres vulgares: Jasmine.

Técnica de la iconografía: Flores en pietra dura.

Estilo morfológico primario: Figurativo naturalista.

Iconografía: Figura 10A.

\section{Lonicera henryi Hemsl.}

Familia: Caprifoliaceae.

Estatus: Introducida de China.

Nombres vulgares: Honeysuckle.

Técnica de la iconografía: Flores en pietra dura.

Estilo morfológico primario: Figurativo naturalista.

Iconografía: Figura 5D.

\section{Luffa cylindrica M. Roem.}

Familia: Cucurbitaceae.

Estatus: Introducida (?).

Nombres vulgares: Loofa.

Técnica de la iconografía: Flores y frutos en arenisca roja (en la mezquita).

Estilo morfológico primario: Figurativo naturalista.

Iconografía: Figura 4C. 


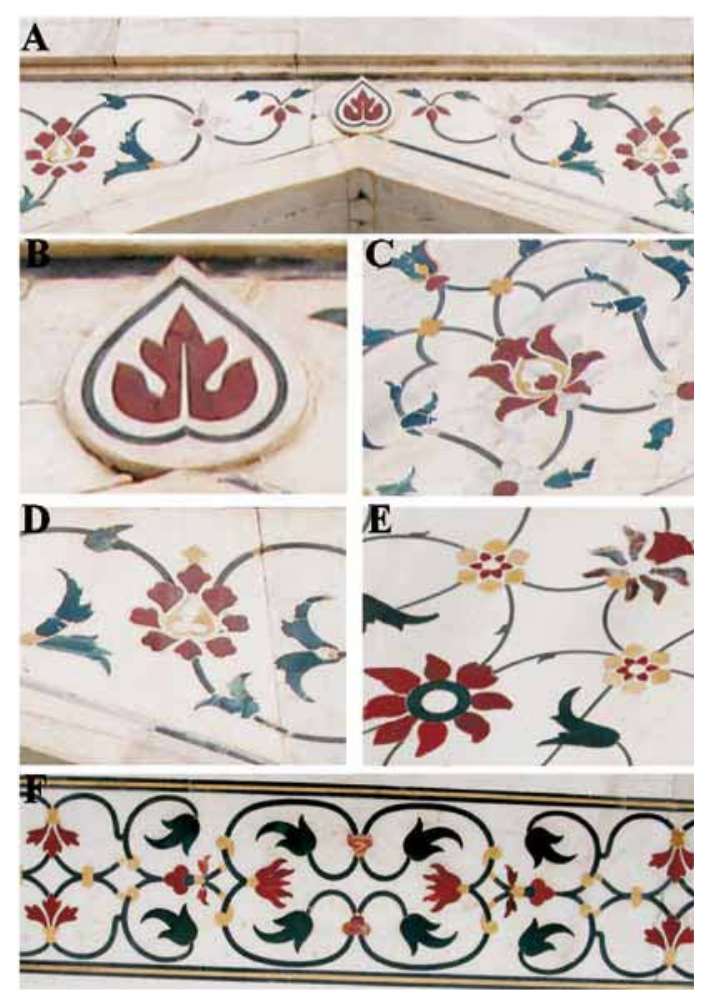

Figura 10. Motivos vegetales representados por medio de la técnica de la "pietra dura" en el mausoleo del Taj Mahal. A. Decoración superior de un arco lateral externo del mausoleo, donde se aprecian diferentes especies, entre éstas Jasminum sp. (correspondiente a las dos flores grisáceas de cinco pétalos y centro redondo negruzco, las cuales están una a cada lado de la hoja central idealizada de Ficus religiosa); B. Hoja idealizada de Acanthus cf. mollis L., la cual se encuentra "encerrada" en una hoja de Ficus religiosa L.; C. Flor roja central asignable a Aquilegia sp.; D. Flor roja central asignable a Thunbergia mysorensis (Wight) T. Anderson (vista frontal de la flor); E. Las dos flores amarillas con centros rojos son asignadas a Potentilla $\mathrm{cf}$. cuneata Wall. ex Lehm., la imagen roja con un disco central oscuro es asignada a un capítulo de Centaurea sp., mientras que la flor del extremo superior derecho es asignable a Clematis sp.; F. Cinta con Dianthus sp. (correspondiente a los dos pares de las flores rojas con sus partes distales crenadas; cada flor se encuentra enfrentada en los extremos izquierdo y derecho de la figura; cabe destacar que las flores asignables a Dianthus sp. se encuentran en vista lateral y no frontal, por lo que aparecen representadas con sólo tres pétalos), Butea monosperma (Lam.) Taub. (flores negruzcas), Lilium sp. (correspondiente a las dos flores centrales acompañadas de cuatro flores de Butea monosper$m a$ ) y dos flores centro-laterales de Clematis sp. (fotografías: D. Giraldo-Cañas).
Nelumbo nucifera Gaertn.

Familia: Nelumbonaceae.

Estatus: Nativa.

Nombres vulgares: Indian lotus, lotus, sacred lotus.

Técnica de la iconografía: Flores en pietra dura, así como en alto relieve en mármol (en la base y el remate de algunas columnas).

Estilo morfológico primario: Figurativo naturalista. Iconografía: Figuras 5F y $11 \mathrm{~B}$.

\section{Papaver orientale L.}

Familia: Papaveraceae.

Estatus: Nativa.

Nombres vulgares: Oriental poppy, poppy.

Técnica de la iconografía: Flores en pietra dura, frutos en alto relieve en mármol.

Estilo morfológico primario: Figurativo naturalista.

Iconografía: Figura 6K.

\section{Potentilla cf. cuneata Wall. ex Lehm.}

Familia: Rosaceae.

Estatus: Nativa de los Himalayas.

Nombres vulgares: Cinquefoil, five finger cinquefoil.

Técnica de la iconografía: Flores en pietra dura.

Estilo morfológico primario: Figurativo idealista.

Iconografía: Figura 10E.

Primula cf. sinopurpurea Balf. f. ex Hutch.

Familia: Primulaceae.

Estatus: Introducida de China.

Nombres vulgares: Primrose.

Técnica de la iconografía: Planta completa en pietra dura. Estilo morfológico primario: Figurativo naturalista.

Iconografía: Figura 6L.

\section{Punica granatum L.}

Familia: Lythraceae.

Estatus: Nativa (?).

Nombres vulgares: Pomegranate.

Técnica de la iconografía: Flores y frutos en pietra dura. Estilo morfológico primario: Figurativo naturalista. Iconografía: Figuras 5B y $6 \mathrm{G}$.

\section{Rosa sp.}

Familia: Rosaceae.

Estatus: Introducida de Europa.

Nombres vulgares: Rose.

Técnica de la iconografía: Flores en pietra dura.

Estilo morfológico primario: Figurativo idealista.

\section{Thunbergia mysorensis (Wight) T. Anderson}

Familia: Acanthaceae.

Estatus: Nativa. 


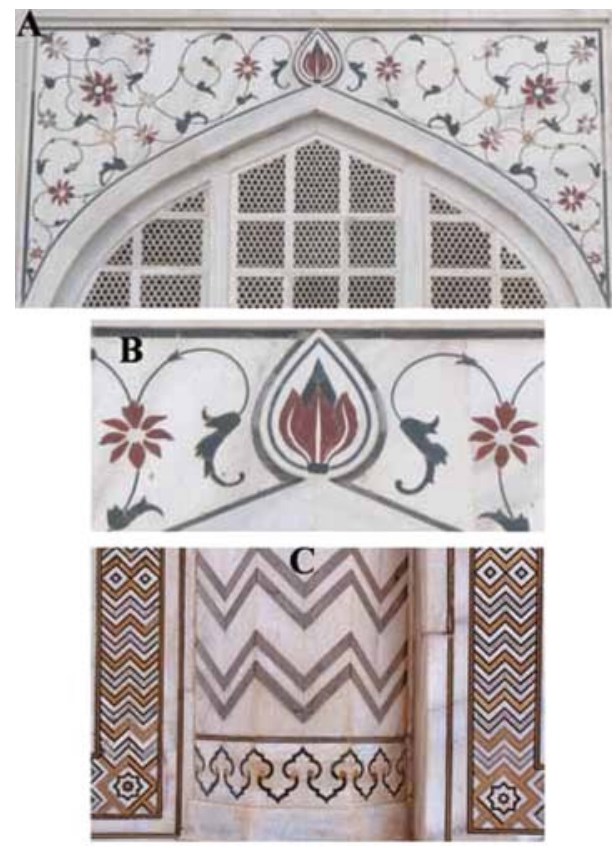

Figura 11. A. Decoración con motivos florales en "pietra dura" en una ventana lateral del mausoleo del Taj Mahal; B. Flor de Nelumbo nucifera Gaertn., "encerrada" en una hoja de Ficus religiosa L. y acompañada simétricamente a cada lado por flores de Thunbergia mysorensis (Wight) T. Anderson (correspondiente a las flores negruzcas en vista lateral) y de Centaurea sp. (correspondiente a los dos capítulos rojos laterales); C. Motivos vegetales sin asignación taxonómica, en los que se puede apreciar tanto representaciones abstractas geométricas (flores, además de líneas y rombos superpuestos) como representaciones abstractas figurativas (siluetas idealizadas de árboles) (fotografías: D. Giraldo-Cañas).

Nombres vulgares: Brick and butter vine, clock vine, dolls shoes, mysore clock vine.

Técnica de la iconografía: Flores en pietra dura. Estilo morfológico primario: Figurativo idealista. Iconografía: Figuras 5C, 10D y 11B.

\section{Vitis vinifera $\mathrm{L}$.}

Familia: Vitaceae.

Estatus: Introducida del Mediterráneo.

Nombres vulgares: Grape, grape vine.

Técnica de la iconografía: Hojas en alto relieve en mármol. Estilo morfológico primario: Figurativo naturalista.

Iconografía: Figura 8F.

\section{Eudicotiledónea indeterminada}

Familia: Sin asignación.

Técnica de la iconografía: Hojas en alto relieve en arenisca roja (las hojas consideradas están dispuestas en ramas floríferas de dos monocotiledóneas combinadas, Iris cf. germa- nica y Narcissus sp., las que se encuentran en varios paneles de la mezquita).

Estilo morfológico primario: Figurativo naturalista. Iconografía: Michell (2007: 171).

\section{Motivos vegetales abstractos sin asignación taxonómica}

A las flores con diseños geométricos, las cuales son muy escasas en el complejo del Taj Mahal, no se les pudo realizar ninguna asignación taxonómica. También había varios tipos de figuras que idealizaban siluetas de árboles.

Técnica de la iconografía: Flores en pietra dura [tanto en mármol (en el mausoleo) como en arenisca roja (en la mezquita)], siluetas idealizadas de árboles [tanto en bajo relieve en mármol (en el mausoleo) como en pietra dura (en el mausoleo y en el portal del complejo)].

Estilo morfológico primario: Abstracto geométrico (flores) y abstracto figurativo (siluetas de árboles).

Iconografía: Figura 11C.

\section{Motivos vegetales (hojas) sin asignación taxonómica}

En varios paneles en mármol y en arenisca roja había diversas hojas, las cuales acompañaban diferentes flores. No obstante, varias de estas hojas no correspondían con las flores, de hecho, había hojas de eudicotiledóneas en ramas floríferas de monocotiledóneas. Por tal razón, no se les pudo realizar ninguna asignación taxonómica.

Técnica de la iconografía: Hojas en alto relieve en mármol y arenisca roja.

Estilo morfológico primario: Figurativo, tanto naturalista como idealista.

Con base en lo anterior, la iconografía vegetal del complejo del Taj Mahal se enmarca en su totalidad -en el sentido de Sondereguer (2004) - en los dos estilos primarios, el figurativo (naturalista e idealista) y el abstracto (figurativo y geométrico). No obstante, el estilo figurativo naturalista es el más común, ya que de las 46 especies reconocidas, 31 corresponden a dicho estilo.

La representación del loto (Nelumbo nucifera, flor nacional de la India) es también recurrente en el Taj Mahal, lo que concuerda con su significado de nacimiento, pureza, belleza, espiritualidad y eternidad en muchas culturas y religiones (Patnaik, 1993; Gupta, 1996; Misbach, 2003; O'Connell \& Airey, 2007; Spellman, 2008). En la India también hay una mitología sexual en torno de la flor de loto, ya que ésta simboliza diferentes aspectos de la sexualidad femenina, lo que depende de sus partes y edad (Frownfelter, 2010). Así, 
el loto puede ser un símbolo de "entrañas fructíferas", su pistilo es el feto, sus brotes representan el "virgin cunnus", y cuando el loto se encuentra en flor representa el bostezo de una mujer productiva (Frownfelter, 2010).

La consideración de Cupressus sempervirens en la iconografía analizada está asociada con su simbología inherente a la muerte, de ahí su nombre en inglés "funeral cypress", y su frecuente uso -no sólo como un elemento recurrente en la iconografía mogola, sino también como un elemento vivo empleado en los jardines mogoles y persas (Giraldo-Cañas, obs. pers.) así como ottomanos (And, 1978)- convierten a esta especie como una de las más representadas en diferentes edificaciones mogolas. Esta especie en Asia también es símbolo de longevidad y fortaleza (O'Connell \& Airey, 2007). Entre tanto, en la antigua Persia, los tulipanes (Tulipa spp.) constituían un símbolo del amor perfecto, cuyas flores se encontrarían en los jardines del paraíso (O'Connell \& Airey, 2007). Durante el período Ottomano, los tulipanes se convirtieron en símbolo de divinidad y llegaron a ser el emblema de los gobernantes ottomanos (O'Connell \& Airey, 2007). Según O'Connell \& Airey (2007), en el Corán se dice que las granadas (Punica granatum) fueron uno de los regalos de Allah, y estas frutas están asociadas con la fertilidad, la unidad, el amor, el matrimonio y también con la muerte. Del mismo modo, el Ficus carica es símbolo de fecundidad, enseñanza moral e inmortalidad; mientras que el Ficus religio$s a$ representa la creación, la vida y la preparación para el paraíso.

La mayoría de las especies empleadas en la iconografía del Taj Mahal corresponde a elementos principalmente simbólicos, más que religiosos. Así, las flores tetrámeras simbolizan las cuatro direcciones del espacio (norte, sur, este y oeste); el centro de la flor representa el Dios Supremo, el cual controla equitativamente las cuatro direcciones del espacio. Adicionalmente, los cuatro pétalos representan los cuatro estados de la vida (infancia, adolescencia, adultez y vejez). Las flores pentámeras simbolizan los cinco sentidos (vista, olfato, tacto, gusto y oído), así como los cinco elementos básicos (fuego, éter, tierra, agua y viento). Entre tanto, las flores hexámeras representan las seis direcciones del espacio (norte, sur, este, oeste, arriba y abajo), así como los seis atributos del Señor Supremo (juicio, fuerza, fama, compasión, riqueza y fuerzas divinas) (Gupta, 1996). Véase Misbach (2003) para una completa interpretación de las plantas en la Cultura Mogola.

Se destaca el empleo de especies ajenas a la flora india, las que corresponden, en buena medida, a elementos nativos de Asia Central, y su uso se deriva de la pasión de los mogoles por la flora de su mundo islámico, situación que ya había sido destacada por Wescoat Jr. (1999), Kossak \& Watts
(2001), Misbach (2003) y Michell (2007) para otras edificaciones mogolas de la India. Asimismo, en la iconografía del complejo del Taj Mahal hay especies introducidas de Europa y el Mediterráneo, las cuales evidenciarían la influencia de los europeos que participaron en su construcción (véase Havell, 1920). Plantas ajenas a la flora india que han sido empleadas en la iconografía antigua, también fueron destacadas por Gupta (1996) en su estudio de templos budistas, hindúes y jaines.

Del mismo modo, es necesario destacar el uso de una especie de la América tropical en la iconografía del Taj Mahal ( Fuchsia cf. venusta), situación totalmente creible, ya que desde tiempos remotos, más o menos hacia el año 1500 (Martínez, 1988; Gupta, 1996) e incluso antes (Gupta, 1996; Menzies, 2006), se introdujeron numerosas plantas americanas al continente asiático (Martínez, 1988), tales como los ajíes o chiles (Martínez, 1988; Gupta, 1996; Kossak \& Watts, 2001), el acapulco, las calabazas, el cascalote o dividiví, el espino de playa, el guachimole o tamarindo de manila, el bricho o mezquitillo, el fríjol, la guayaba, el mezquite, las patatas, la pimienta redonda de árbol (Martínez, 1988), el anón, el balazo, el girasol, el maraco, el marañón (Gupta, 1996), el maíz (Martínez, 1988; Johannessen \& Parker, 1989; Gupta, 1996; Menzies, 2006), la piña (Martínez, 1988; Gupta, 1996), el tabaco (Michell, 2007), entre otras, y es de esperarse que también se hayan introducido plantas ornamentales desde el continente americano. Según Gupta (1996: 187), muchas de las plantas introducidas a la India fueron llevadas por los portugueses en el siglo XVI.

Es interesante destacar el uso de la flora en la iconografía del Taj Mahal como centro de la imagen, a diferencia de las iconografías occidentales y las del período Ottomano, en donde la flora y en general, la naturaleza incluida en las iconografías no es el centro de la imagen sino un acompañamiento del o los personajes representados, sean éstos un rey, un gobernante, un noble, un santo, una virgen, un ángel o un cristo (véanse And, 1978; Leal del Castillo, 2001; O'Connell \& Airey, 2007). Igualmente, es necesario destacar la ausencia de motivos faunísticos en la iconografía del Taj Mahal, los cuales pueden ser abundantes en otros tipos de edificaciones antiguas de la India, entre las que se destaca el Templo de Karni Mata de Rajasthán -un templo correspondiente al Estilo Mogol Tardío-, donde la iconografía en relieve en mármol combina, frecuentemente, plantas y animales (Giraldo-Cañas, 2013), igual situación se presenta en varias edificaciones mogolas, no sólo de la India sino también de Pakistán (Misbach, 2003).

Es curiosa la escasa representación de especies arbóreas (e.g. Butea monosperma, Cupressus sempervirens, Ficus carica, 
Ficus religiosa, Magnolia sp. y Punica granatum) y de frutos e infrutescencias (e.g. Luffa cylindrica, Magnolia sp., Papaver orientale y Punica granatum) en la iconografía del complejo del Taj Mahal. Es necesario destacar una diferencia notable en la consideración de las especies empleadas en la iconografía mogola, ya que la mayoría de las especies corresponde a elementos de jardinería y ornato, a diferencia de las antiguas iconografías vegetales americanas, en donde la mayoría de las especies usadas representa especies alimenticias o de uso mágico-religioso, como por ejemplo en Bolivia, Colombia, Ecuador, Guatemala, México y Perú (Giraldo-Cañas, obs. pers.).

\section{Conclusiones}

La iconografía vegetal en piedra del Taj Mahal constituye un valioso tesoro de ornamentación arquitectónica, representado en una rica, delicada y exquisita muestra de diferentes especies, plasmadas principalmente en mármol y en segunda medida, en piedras preciosas y semipreciosas, así como en arenisca roja. Dicha iconografía representa un estudio de devoción artística y en palabras de Bahn (2007), lo más valioso de este tesoro no son sólo las formas artísticas, sino la información que éstas poseen.

La excepcional riqueza de formas y el número de especies vegetales representadas en el Taj Mahal, se enmarcan en lo hallado por Wilson (2011), quien para otras edificaciones destacó que las ubicadas en el noroeste de la India, son las que presentan la mayor diversidad en ornamentación arquitectónica. Por otra parte, Gupta (1996) documentó la asignación taxonómica de 74 especies vegetales usadas en la iconografía de numerosos templos budistas, hindúes y jaines de la India, mientras que aquí se documentan 46 especies sólo para un sitio, el Taj Mahal.

A pesar de la amplia gama de investigaciones en torno de sus culturas e historia, la India continúa mostrando, cada vez más, nuevo conocimiento y nuevas posibilidades de investigación. Así, se hacen necesarios más análisis integrales cualitativos y cuantitativos de la iconografía vegetal del amplio conjunto de edificaciones indias, tanto antiguas como recientes, con lo que se enriquecerá enormemente el conocimiento botánico de este majestuoso y maravilloso país. Además, con este tipo de estudios se documentaría, en buena medida, el grado de apropiación cultural de los recursos vegetales con su asignación taxonómica por parte de los diferentes pueblos indios.

Es lamentable el estado de conservación de algunas partes del Taj Mahal, en donde se evidencia el deterioro por el tiempo o por parte de algunos visitantes inescrupulosos, ya que son evidentes los robos de algunas piedras preciosas y semipreciosas de la iconografía en "pietra dura", robos que fueron iniciados y promovidos desvergonzadamente por los ingleses en el siglo XIX (véase Baxter et al., 2011).

No obstante la enorme diversidad florística de la India (Venu, 1998), el país no cuenta con suficientes taxónomos (Raj, 2010; Ali \& Choudhary, 2011) y quizás por esta situación, el estudio y el análisis de la numerosa iconografía vegetal con su respectiva asignación taxonómica, a lo largo y ancho del país, es una tarea que aún permanece sin desarrollarse. En este sentido, este trabajo empieza a cubrir esos vacíos de información de la iconografía vegetal asiática, toda vez que de las escasas investigaciones sobre esta temática, la mayoría de éstas se ha centrado en las iconografías europea y americana (véase Pavord, 2005, así como las demás referencias consignadas en la literatura citada), sin embargo, la iconografía asiática es mucho más antigua y quizás más numerosa.

\section{Agradecimientos}

Al Instituto de Ciencias Naturales, al Herbario Nacional Colombiano "COL" y a la Universidad Nacional de Colombia (Bogotá D. C.) por todas las facilidades que me brindó para la preparación de este trabajo. A los señores Jusset Sabagh, Prem Shankar Priyadarsi y Nilo Kumar por su valiosa colaboración y compañía durante los viajes por la India. A mis amigos por su grata compañía en la India. A los diferentes pueblos de la India, por su amabilidad y generosa hospitalidad. Al Prof. Dr. Santiago Díaz Piedrahita (COL) por sus valiosos comentarios y enriquecedora evaluación. Al Dr. Dairon Cárdenas, director-curador del Herbario Amazónico Colombiano "COAH” (Bogotá D. C.), por su amable y permanente colaboración al permitir consultar las colecciones de dicho herbario y por el obsequio de valiosa bibliografía. A la Prof. Dra. Rina Kamenetsky Goldstein (Institute of Plant Sciences, The Volcani Center, Israel) y al Prof. Dr. Jules Janick (Purdue University, West Lafayette, Indiana, EE.UU.), por permitir el uso de las figuras de su artículo "Janick, J., R. Kamenetsky \& S. H. Puttaswamy. 2010. Horticulture of the Taj Mahal: Gardens of the imagination. Chronica Horticulturae 50: 30-33". Al Prof. Dr. Carlos Parra (COL) por la consecución de valiosa bibliografía. Este artículo se deriva del proyecto "Análisis de la iconografía vegetal en varias culturas y épocas" formulado por D. Giraldo-Cañas de la Universidad Nacional de Colombia (Bogotá D. C.). A todos los miembros del Comité Editorial, así como a los evaluadores anónimos, por sus valiosos comentarios.

\section{Referencias}

Ali, M. A. \& R. K. Choudhary. 2011. India needs more plant taxonomists. Nature 471: 37. 
And, M. 1978. Turkish miniature painting. The Ottoman Period. Dost Yayinlari, Ankara.

Anónimo. 2007. The garden flower book. Murdoch Books Pty Ltd., Millers Point.

Antei, G. 1997. Flora Columbiae. Karsten. Tomos I y II. Seguros BolívarOP Gráficas Ltda., Bogotá D. C.

Bahn, P. G. 2007. Preface. En: P. G. Bahn (ed.), The world's great archaeological treasures: 6-9. Barnes \& Noble, Inc., Nueva York.

Baxter, J., R. Burton, R. Cavendish, P. Clarkson, E. Cruwys, B. Riffenburgh \& N. Williams. 2011. 100 Great wonders of the world. A Collection of the world's awe-inspiring places, buildings and landscapes. AA Media Ltd.-Metro Books, Nueva York.

Bhatla, N., T. Mukherjee \& G. Singh. 1984. Plants: traditional worshipping. Indian Journal of History of Science 19: 37-42.

Bye, R. \& E. Linares. 1999. Plantas medicinales del México prehispánico. Arqueología Mexicana 7: 4-13.

Cervantes, M. 2006. El pasado prehispánico en la alimentación y el pensamiento de hoy. Arqueología Mexicana 13: 18-25.

Christenhusz, M. J. M., J. L. Reveal, A. Farjon, M. F. Gardner, R. R. Mill \& M. W. Chase. 2011. A new classification and linear sequence of extant gymnosperms. Phytotaxa 19: 55-70.

Coomaraswamy, A. K. 1928. Early Indian iconography. I. Eastern Art 1: $33-41$.

Coomaraswamy, A. K. 1929. Early Indian iconography. II. Eastern Art 1: 175-189.

Coomaraswamy, A. K. 1998. Elements of Buddhist iconography. Munshiram Manoharlal Publishers Pvt. Ltd., Nueva Delhi.

Cowen, D. V. 1952. Flowering trees and shrubs in India. $2^{\text {da. }}$ ed., Thacker and Co. Ltd., Mumbai.

Dadlani, C. 2010. The "Palais Indiens" Collection of 1774: Representing Mughal Architecture in late eighteenth-century India. Ars Orient 39: 175-197.

Dahlgren, R. M. T. \& H. T. Clifford. 1982. The Monocotyledons: A comparative study. Academic Press Inc. Ltd., Londres.

Dahlgren, R. M. T., H. T. Clifford \& P. F. Yeo. 1985. The families of the Monocotyledons. Structure, evolution, and taxonomy. SpringerVerlag, Berlín.

Daunay, M. C. \& J. Janick. 2007. History and iconography of eggplant. Chronica Horticulturae 47: 16-22.

Daunay, M. C. \& J. Janick. 2008. Early history and iconography of the Solanaceae: 2. Potato. SOL Newsletter 21: 5-7.

Daunay, M. C., E. Jullian, A. Whipkey \& J. Janick. 2007a. Eggplant and capsicum peppers: Historical texts and images. Progress in Research in Capsicum \& Eggplant: 13-21. Warsaw University Life Sciences Press, Varsovia.

Daunay, M. C., H. Laterrot \& J. Janick. 2007b. Iconography of the Solanaceae from antiquity to the xvith century: A rich source of information on genetic diversity and uses. Acta Horticulturae 745: 59-88.

Daunay, M. C., H. Laterrot \& J. Janick. 2008. Iconography and history of Solanaceae: Antiquity to the 17th century. Horticultural Reviews 34: 1-111.

De La Sota, E. R. 1982. La taxonomía y la revolución en las ciencias biológicas. Monografía nro. 3, serie de Biología, Secretaría General de la Organización de los Estados Americanos, Programa Regional de Desarrollo Científico y Tecnólogico, Washington D. C.

De Rosamel, C. \& V. Heinrichs. 2006. El gran libro de las especias. Orígenes, historia, características, propiedades. Editorial De Vecchi S. A. U., Barcelona.
Dhar, P. P. 2011. A history of Art History. The Indian context. En: P. P. Dhar (ed.), Indian art history. Changing perspectives: 1-32. D. K. Printworld (P) Ltd.-National Museum Institute, Nueva Delhi.

Díaz, D. 1999. Xochipilli, príncipe de las flores. Arqueología Mexicana 7: 52-53.

Díaz-Piedrahita, S. 1991. La botánica en Colombia, hechos notables en su desarrollo. Colección Enrique Pérez-Arbeláez No. 6, Academia Colombiana de Ciencias Exactas, Físicas y Naturales, Bogotá D. C.

Díaz-Piedrahita, S. 2000. Matíz y los dos Mutis. Orígenes de la anatomía vegetal y de la sinanterología en América. Colección Enrique PérezArbeláez No. 14, Academia Colombiana de Ciencias Exactas, Físicas y Naturales, Bogotá D. C.

Díaz-Piedrahita, S. \& J. L. Fernández Alonso. 2012. Unos bocetos atribuidos a Francisco Javier Matís (1763-1851). ¿Autenticidad o fraude? Revista Acad. Colomb. Ci. Exact. 36 (140): 399-409.

Drury, H. 1864. Hand-book of the Indian Flora; being a guide to all the flowering plants hitherto describe as indigenous to the Continent of India. Trabancore Sircar Press, Madras.

Eisendrath, E. R. 1961. Portraits of Plants. A Limited Study of the "Icones". Ann. Missouri Bot. Gard. 48: 291-327.

Fernández Pérez, A. 1989. La botánica de la Sagrada Biblia. Primera Parte. Revista Novedades Colombianas 1: 43-54.

Fernández Pérez, A. 1990. La botánica de la Sagrada Biblia. Segunda Parte. Revista Novedades Colombianas 2: 42-51.

Folkard, R. 1884. Plant lore, legends, and lyrics. Myths, traditions, superstitions, and folklore of the plant kingdom. Sampson Low, Marston, Searle, and Rivington, Londres.

Fresquet Febrer, J. L. \& M. L. López Terrada. 1999. Plantas mexicanas en Europa en el siglo Xvi. Arqueología Mexicana 7: 38-43.

Frownfelter, A. 2010. Flower symbolism as female sexual metaphor. Senior Honors Theses, Eastern Michigan University, Ypsilanti.

Furlani Pedoja, A. 2006. El calendario completo para el huerto y el jardín. Editorial De Vecchi S. A. U., Barcelona.

Giraldo-Cañas, D. 2013. La iconografía vegetal del templo Karni Mata (Rajasthán, India). Manuscrito en evaluación.

Goel, N. 2007. Birds and animals in Indian art - The Mughal Artist as a naturalist. Exotic India Art Pvt Ltd. http://www.exoticindia.es/article/ nature (consultado el 5 de febrero de 2013).

Goldber, A. 1989. Classification, evolution, and phylogeny of the families of Monocotyledons. Smithsonian Contributions to Botany 71: 1-74.

Gopinatha Rao, T. A. 1914. Elements of Hindu iconography. The Law Printing House, Madras.

Gupta, S. M. 1996. Plants in Indian temple art. BR Publishing Corporation, Delhi.

Gupta, S. M. 2001. Plant myths and traditions in India. Munshiram Manoharlal Publishers Pvt. Ltd., Nueva Delhi.

Havell, E. B. 1920. A handbook of Indian Art. John Murray, Londres.

Hummer, K. E. \& J. Janick. 2007. Rubus iconography: Antiquity to the Renaissance. Acta Horticulturae 759: 89-105.

Heyden, D. 1983. Mitología y simbolismo de la flora en el México prehispánico. Universidad Nacional Autónoma de México, México D. F.

Janick, J. 2007a. Fruits of the Bibles. HortScience 42: 1072-1076.

Janick, J. 2007b. Art as a source of information on horticultural technology. Acta Horticulturae 759: 69-88.

Janick, J. 2010. Plant iconography and art: Source of information on horticultural technology. Bulletin UASVM Horticulture 67: 11-23.

Janick, J. 2012. Revelations from Histoire Naturelle des Indes known as 
The Drake Manuscript: Horticulture and History. Chronica Horticulturae 52: 14-22.

Janick, J. \& G. Caneva. 2005. The first images of maize in Europe. Maydica 50: 71-80.

Janick, J. \& M. C. Daunay. 2007. History and iconography of the Solanaceae: 1 . Mandrake, a plant at the intersection of reason and irrationality. SOL Newsletter 14: 3-4.

Janick, J., R. Kamenetsky \& S. H. Puttaswamy. 2010. Horticulture of the Taj Mahal: Gardens of the imagination. Chronica Horticulturae 50: $30-33$.

Janick, J. \& H. S. Paris. 2006a. The cucurbit images (1515-1518) of the Villa Farnesina, Rome. Annals of Botany 97: 165-176.

Janick, J. \& H. S. Paris. 2006b. Old world cucubits in plant iconography of the Renaissance. Proc. Cucurbitaceae 2006: 341-348. Universal Press, Raleigh, North Carolina.

Johannessen, C. L. \& A. Z. Parker. 1989. Maize ears sculptured in 12th and 13th Century A.D. India as indicators of Pre-Columbian diffusion. Economic Botany 43: 164-180.

Jones, D. L. 1993. Cycads of the world. Smithsonian Institution Press, Washington D. C.

Joshi, M. C. 2012. Hand-book of Indian medicinal plants. Scientific Publishers India, Jodhpur.

Karolia, A. \& B. Ladia. 2012. Traditional textiles and costumes of Karbi and Biate tribes of Meghalaya. Indian Journal of Traditional Knowledge 11: 309-316.

Kennedy, T. 2007. The notion of hierarchy: The "Parchin Kari" Programme at the Taj Mahal. Archnet-Int. J. Arch. Res. 1: 105-121.

Kossak, S. M. \& E. W. Watts. 2001. The art of South and Southeast Asia. A resource for educators. The Metropolitan Museum of Art, Nueva York.

Kumar Sud, R. \& S. Kumar. 2004. Herbs: Culinary, medicinal, aromatic (secrets and human happiness). Scientific Publishers India, Jodhpur.

Leal del Castillo, M. R. 2001. Importancia de la naturaleza y el arte en el proceso evangelizador. En: Anónimo (ed.), Arte y naturaleza en la Colonia: 97-185. Museo de Arte Colonial-Ministerio de CulturaUniversidad Nacional de Colombia, Bogotá D. C.

León-Portilla, M. 2006. Las flores en la poesía náhuatl. Arqueología Mexicana 13: 42-45.

Linares, E. \& R. Bye. 2006. Las plantas ornamentales en la obra de Francisco Hernández "El Preguntador del Rey". Arqueología Mexicana 13: 48- 57.

Lozoya, X. 1999. Un paraíso de plantas medicinales. Arqueología Mexicana 7: 14-21.

Luna, A. 1996. La flora representada en la iconografía pictórica. La pintura mural prehispánica en México (Boletín Informático) 5: 369-389.

Mabberley, D. J. 1998. The plant-book. A portable dictionary of the vascular plants. Cambridge University Press, Cambridge.

Macaulay-Lewis, E. 2010. Imported Exotica: Approaches to the study of the ancient plant trade. Bollettino di Archeologia on line 1 (volumen especial): 16-26.

MacDonell, A. A. 1918. Development of Hindu iconography. Journal of the Royal Asiatic Society of Great Britain and Ireland 1918: 526-535.

Martínez, M. Á. 1988. Contribuciones iberoamericanas al mundo. Botánica, medicina, agricultura. Biblioteca Iberoamericana, Ediciones Anaya S. A., Madrid

Mason, R., T. Morphet \& S. Prosalendis. 2006. Reading scientific images. The iconography of evolution. HSRC Press, Cape Town.
Mathur, M. 2012. Herbal aphrodisiac their need, biology and status: global and regional scenario. Journal of Natural Products 5: 131-146.

Menzies, G. 2006. 1421, el año en que China descubrió el mundo. Novoprint, S. A., Barcelona.

Michell, G. 2007. The majesty of Mughal decoration. The art and architecture of Islamic India. Thames \& Hudson Inc., Nueva York.

Mikolajski, A. 2009. The illustrated encyclopedia of garden plants. Hermes House-Anness Publishing Ltd., Londres.

Misbah, G. 2003. Floral decoration in Mughal buildings, Lahore. Ph.D. Thesis, Taxila Institute of Asian Civilizations, Quaid-i-Azam University, Islamabad.

Munsterberg, M. 2009. Writing about art. Create Space Independent Publishing Platform, Nueva York.

Nayar, T. S., S. Binu \& P. Pushpangadan. 1999. Uses of Plants and Plant Products in Traditional Indian Mural Paintings. Economic Botany 53: 41-50.

Nieto Olarte, M. 2000. Remedios para el imperio. Historia natural y la apropiación del Nuevo Mundo. Instituto Colombiano de Antropología e Historia, Bogotá D. C.

O'Connell, M. \& R. Airey. 2007. The complete encyclopedia of signs and symbols. Hermes House-Anness Publishing Ltd., Londres.

Pacheco, M. A. 2006. Los antiguos dioses y las flores. Arqueología Mexicana 13: 46-47.

Page, S. \& M. Olds. 2004. Botanica. The illustrated encyclopedia of over 10,000 garden plants and how to cultivate them. Barnes \& Noble Books, Nueva York.

Pang, H. 1992. Pre-Columbian Art: Investigations and insights. University of Oklahoma Press, Norman.

Patil, D. A. 2012. Indian ethnobotany: genesis through ages. World Journal of Science and Technology 2: 1-14.

Patnaik, N. 1993. The garden of life. An introduction to the healing plants of India. Doubleday Publishers, Nueva York.

Pavord, A. 2005. The naming of names. The search for order in the world of plants. Bloomsbury Publishing, Nueva York.

Pridgeon, A. 2006. The illustrated encyclopedia of orchids. Timber Press, Inc., Portland.

Proulx, D. A. 2006. A sourcebook of Nasca ceramic iconography. Reading a culture through its art. University of Iowa Press, Iowa.

Raezer, D. \& J. Raezer. 2012. Highlights of India: Delhi, Agra \& the Taj Mahal. Approach Guides, Nueva York.

Raj, M. S. K. 2010. Global biodiversity crisis and priorities in Indian plant systematics. Current Science 99: 1491.

Randhawa, M. S. 1957. Flowering trees in India. Indian Council of Agricultural Research, Nueva Delhi.

Rao, T. A. G. 1916. Elements of Hindu iconography. The Law Printing House, Madras.

Real Academia Española de la Lengua. 2001. Diccionario de la lengua española. Vigésima segunda edición. Editorial Espasa Calpe S. A., Madrid.

Reveal, J. L. \& M. W. Chase. 2011. APG III: Bibliographical information and synonymy of Magnoliidae. Phytotaxa 19: 71-134.

Rueda González, A. 2001. Sensibilidad alegórica: naturaleza de la imagen e imagen de la naturaleza. En: Anónimo (ed.), Arte y naturaleza en la Colonia: 13-95. Museo de Arte Colonial-Ministerio de CulturaUniversidad Nacional de Colombia, Bogotá D. C.

Schultes, R. E. \& A. Hofmann. 2000. Plantas de los dioses. Fondo de Cultura Económica, México D. F. 
Sharma, P., I. Gupta \& P. Jha. 2009. New aspects related to origin and development of Mughal inlay art in India. Anistoriton Journal 11: 1-12.

Singh, G. 2010. Plant systematics. An integrated approach. $3^{\text {era. }}$ ed., Science Publishers, Enfield, New Hampshire.

Skinner, C. M. 1911. Myths and legends of flowers, trees, fruits, and plants in all ages and in all climes. $3^{\text {era }}$. ed., J. B. Lippincott Company, Filadelfia.

Smith, E. W. 1901. Moghul colour decoration of Agra. Part I. Archaeological Survey of India, Supdt., Govt. Press, Allahabad.

Sondereguer, C. 2004. Manual de iconografia precolombina y su análisis morfológico. Cronología y estética. Mesoamérica, Centroamérica, Suramérica, 1300 a.C. - 1532 d.C. Facultad de Arquitectura, Diseño y Urbanismo, Universidad de Buenos Aires, Buenos Aires.

Sood, S. K., S. Rana \& T. N. Lakhanpal. 2005a. Ethnic aphrodisiac plants. Scientific Publishers India, Jodhpur.

Sood, S. K., V. Thakur \& T. N. Lakhanpal. 2005b. Sacred and magicoreligious plants of India. Scientific Publishers India, Jodhpur.

Spellman, C. 2008. Florigrafia. El lenguaje de las flores. Mitos y leyendas del mundo. Editorial Oveja Negra-Quintero Editores, Bogotá D. C.

Stolarczyk, J. \& J. Janick. 2011. Carrot: History and iconography. Chronica Horticulturae 51: 13-18.

Swerdlow, J. L. 2000. Nature's medicine. Plants that heal. A chronicle of mankind's search for healing plants through the ages. National Geographic Society, Washington D. C.

Taube, K. A. 1986. The Teotihuacan Cave of Origin: The iconography and architecture of emergence mythology in Mesoamerica and the American Southwest. Anthropology and Aesthetics 12: 51-82.

Tawari, L. 2003. Ancient Indian Botany and Taxonomy. www.infinityfoundation.com/mandala/ t_es/t_es_tiwar_botany_frameset.htm (consultado el 16 de enero de 2013).

Teron, R. \& S. K. Borthakur. 2012. Biological motifs and designs on traditional costumes among Karbis of Assam. Indian Journal of Traditional Knowledge 11: 305-308.

Torfrida, M. 1944. Nurseries of heaven. Wild flowers of India. Thacker and Co. Ltd., Mumbai.

Tyldesley, J. A. \& P. G. Bahn. 1983. Use of plants in the European Paleolithic: A review of the evidence. Quarternary Science Review 2: 53-83.
Uriarte, M. T. 2006. Flores en la pintura mural prehispánica. Arqueología Mexicana 13: 36-41.

Velasco Lozano, A. M. L. 1999. Representación de algunas plantas medicinales en la arqueología. Arqueología Mexicana 7: 24-29.

Velasco Lozano, A. M. L. \& D. Nagao. 2006. Mitología y simbolismo de las flores. Revista Arqueología Mexicana 13: 28-35.

Venkateswara, S. V. 1918. The development of Hindu iconography. Journal of the Royal Asiatic Society of Great Britain and Ireland 1918: 519-526.

Venu, P. 1998. A review of floristic diversity inventory and monitoring methodology in India. Proceedings of Indian National Science Academy B64 (5-6): 281-292.

Viesca Treviño, C. 1999. Uso de las plantas medicinales mexicanas. Arqueología Mexicana 7: 30-35.

Villegas, B. (ed.). 1992. Mutis y la Real Expedición Botánica del Nuevo Reyno de Granada. Tomos I y II. Villegas Editores-Lunwerg Editores, Barcelona.

Webb, M. A. \& R. Craze. 2006. The herb \& spice companion. Barnes \& Noble Publishing, Nueva York.

Wescoat Jr., J. L. 1999. Mughal gardens: The re-emergence of comparative possibilities and the wavering of practical concern. En: M. Conan (ed.), Perspectives on garden histories: 107-135. Dumbarton Oaks Research Library and Collection, Washington D.C.

White Olascoaga, L. \& C. Zepeda Gómez. 2005. El paraíso botánico del convento Malinalco, estado de México. Universidad Autónoma del Estado de México, México D. F.

Wilson, H. 2011. Pattern and ornament in the Arts of India. Thames \& Hudson Inc., Nueva York.

Zeven, A. C. \& W. A. Brandenburg. 1986. Use of paintings from the 16th to the 19 th centuries to study the history of domesticated plants. Economic Botany 40: 397-408.

Ziauddin, M. 2005. Role of Persians at the Mughal Court: A historical study, during 1525 A.D. to 1707 A.D. Ph.D. Thesis, University of Balochistan, Quetta.

Recibido: 9 de marzo de 2013

Aceptado para su publicación: 4 de junio de 2013 